\title{
MORE ON OLD ENGLISH PROSODY: MORAIC OR SYLLABIC?
}

\author{
SHIN-ICHI TANAKA \\ University of Tsukuba
}

\begin{abstract}
Proposals for foot structure in Old English have hitherto been restricted mainly to syllable-based accounts and formulated such a phonological process as high vowel deletion in terms of syllable-counting feet. I argue here, however, that syllable-based accounts are inadequate both descriptively and explanatorily even if they utilize two metrical planes, because there are some examples whose stress location is not expected and other processes than high vowel deletion (e.g. resolution, Sievers's Law, and West Germanic gemination) are not captured uniformly. I present an integrated and uniplanar theory of Old English prosody, making judicious use of moras instead of syllables. This amounts to saying that the language is mora-counting.*
\end{abstract}

\section{Introductory Remarks and an Outline of Previous Analyses}

Since the advent of Keyser and O'Neil (1985, hereafter K \& O), Old English has received much due attention not merely because there have been some difficulties in capturing the distribution of its primary and secondary stress but because it has proved to be largely possible to give a metrical account for a well-known segmental rule called high vowel deletion. Some phonologists have tackled these issues by analyzing the language as syllable-counting (K \& O, Suphi (1988), Okazaki (1989), McCully and Hogg (1990), and Yokotani (1991)) while others have shed new light on the topics by treating it as mora-counting (Lahiri and Hulst (1987), Kaminashi (1989), Dresher and Lahiri (1991, henceforth D \& L), Tanaka (1990b, 1991b), Haraguchi and Tanaka (1992)). The issues have given rise

* The topic of this paper (mora-based vs. syllable-based) originated in 1989 from a lively discussion with Masao Okazaki, which has continued so far and led me to the same conclusion as that time after all. I am very indebted to him for his various comments, criticism, and instruction. Thanks also go to the following people for their valuable suggestion and advice: Shosuke Haraguchi, Yukio Hirose, Takeru Honma, and two anonymous $E L$ reviewers. Last but not least, I owe much gratitude to Roger Martin for stylistic improvement. I accept sole responsibility for any inadequacy.

English Linguistics 9 (1992) 284-312 -284-

(C) 1992 by the English Linguistic Society of Japan 
to so much controversy because the precise formulation of stress assignment and segmental rules, including high vowel deletion, relies considerably on what kind of foot the language is taken to have: syllabic or moraic. In either way, a plausible theory of Old English prosody should establish a valid relationship between the Old English stress system and relevant segmental phenomena, and the assigned feet and formulated rules must generate all and only the correct outputs.

The distribution of primary and secondary stress is rather hard to generalize as mentioned above, but it can be stated roughly as follows: primary stress falls on the initial syllable of a word, and secondary stress falls on the penultimate syllable preceded by one heavy syllable or two light syllables (e.g. síngènde 'sing' and ápelinges 'prince' (gen.sg.), but ápeling 'prince' (nom. sg.)) (Okazaki (1989: 144)). However, there are some exceptions to this generalization, which are pointed out by Okazaki. These exceptions divide into two types: (a) háalignèsse 'holiness', where the penult is preceded not by one heavy syllable by two heavy syllables, and (b) wíitelàac 'punishment', where not the penultimate but the final syllable bears secondary stress. Exceptions of the former type are relatively easy to handle in any theoretical framework, ${ }^{2}$ while recent studies do not have a principled account, as they stand, for exceptions of the latter type.

The aim of this paper is to compare a mora-based and a syllable-based approach to Old English stress and related processes and to examine which method makes it possible to give a metrically-coherent explanation, in the sense of D \& L, for exceptions and other apparently-segmental processes.

First, let us review an analysis by Tanaka (1991b), in which Old English stress system is claimed to have the following parameter values for metrical constituents:

(1) a. Mora: all rime segments.

b. Foot - Type: $(*$.)

M M

Direction: Left-to-Right.

Domain: morpheme.

${ }^{1}$ I am grateful to M. Okazaki (p.c., 1991) for pointing out these exceptions.

${ }^{2} \mathrm{D} \& \mathrm{~L}$ do not even account for exceptions of the former type, which are discussed in detail by Tanaka (1991b). And probably, they do not seem to have a clue to exceptions of the latter type. For further problems with D \& L and other studies such as K \& $O$ and Kaminashi (1989), see Tanaka (1991b). 


\section{c. Superfoot - Type: $(*$.) \\ $\mathrm{F} \mathrm{F}$}

Direction: Right-to-left.

d. Phonological word: $(* \quad . \quad$.)

$\mathrm{SF}_{1} \quad \mathrm{SF}_{2} \ldots \mathrm{SF}_{\mathrm{n}}$

Restated informally, all rime segments count as moras in the language; ${ }^{3}$ over moras, binary and left-dominant feet are aligned from left to right with the proviso that the alignment should not cross morpheme boundaries; ${ }^{4}$ over feet, binary and left-dominant superfeet are aligned from right to left; ${ }^{5}$ and finally, an unbounded and left-dominant phonological word is assigned. The manner in which these constituents are constructed can be illustrated as in (2): $:^{6,7}$

(2)
a. $(* \ldots, \ldots)(* \quad \ldots \quad$.
$(*)(* .) \quad.(*)(\ldots .$.
$(*)(*).(*)$
$(*)(\ldots)(*)$
b. $(* .$.
$(* .$.
c. $(* . \quad . . \quad$.
M MM M M MM M
fǽ reld $+u \rightarrow$ fǽ reld+u
$(*).(*)$
$(*).(* .$.
M M M
wérud+u
$(*).(*).(*)$
MM MM M
fúl wìht +u
d. $(* . \quad . \quad) \quad.(* . \quad . \quad$.
e. $(* \quad).(* \quad$.$) f. (*$. $\quad$..)
$(*).(* \quad) \quad.(*).(* \quad$.
$(* \quad).(* \quad$.
$(* . .$.
$\left(*^{*}\right)(*)(*) \quad(*).\left({ }^{*}\right)($.
$(*)(*) \quad(*)($.
$(*).(*$.
MM M M MM M M
$M \quad M \quad M \quad M$
MM MM
níi tèn+u $\rightarrow$ níi tèn+u
$\operatorname{lím}_{+} \mathrm{u} \rightarrow \operatorname{lím}+\mathrm{u}$
wórd + um

${ }^{3}$ For arguments in favor of parametrization of moras, see Haraguchi and Tanaka (1992). Although any rime segment can count as a mora in Old English, we assume that short diphthongs such as $i o, e o$, and $e a$ are assigned only a single mora while long diphthongs such as iio, eeo, and eea two moras.

4 The domain of foot construction is usually a word, but in some languages it is a morpheme. One such language, beside Old English, is Japanese. See Tanaka (1992b).

5 Superfeet were originally introduced into the Old English stress system by Kaminashi (1989).

${ }^{6}$ Here and below, a morpheme boundary is depicted as + .

7 In the general prosodic hierarchy, the mora tier is immediately dominated by the syllable tier as shown schematically below:

(i)

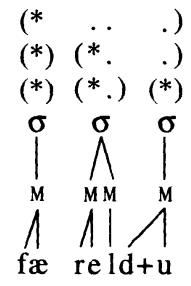


In the prosodic hierarchy, the head of a phonological word represents primary stress and the head of a superfoot represents secondary stress. It should be noticed that when there occurs a stress clash, ${ }^{8}$ the lower of the two adjacent grids are deleted as in (2a), (2d), and (2e), as seems to be attested in all languages with secondary stress that have been investigated so far (cf. Tanaka (1992a, c)).

Second, let us examine Okazaki's (1989) analysis, which is the first to try to account for Old English stress on the basis of the framework put

But for convenience, we do not represent the syllable tier except for sections 3.3. and 3. 4., because we claim that syllables are not relevant to Old English prosody in general. We assume in (i) that constituents on each tier are constructed from the bottom up by prosodic constituent construction (PCC), which applies in accordance with the parameter settings in (1). In constructing moras and syllables, another rule, stray adjunction (SA), is needed to associate stray segments with genuine moras rightward and to associate stray moras with genuine syllables leftward; in other words, this rule is a somewhat generalized version of Hyman's (1985) onset creation rule. Construction of other prosodic constituents above must not violate the Strict Layer Hypothesis, one of the general principles governing the prosodic organization: a prosodic category $C_{i}$ immediately dominates all and only constituents of the category $C_{i-1}$ (Hayes (1989), Tanaka (1990a, 1991a)). As demonstrated by Tanaka (1990a, 1991a), whenever a violation of the principle occurs, refooting (RF) applies as a repair strategy. The prosodic structure of fareldu, then, is derived in the following way (syllables are originally assigned to vowel nuclei only):

(ii)
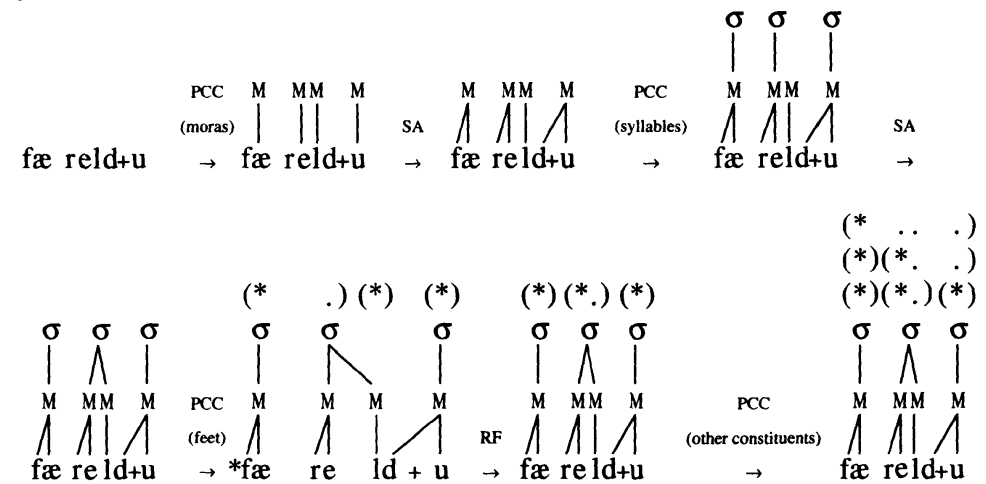

In this case, ordinary foot construction from left to right would produce a violation of the Strict Layer Hypothesis because the second foot immediately dominates not a syllable but a mora, which causes the application of refooting.

${ }^{8}$ A stress clash can be defined in the representations as "any two adjacent *'s on a tier." When clashes occur on the two tiers simultaneously, clash deletion applies from the top down by convention; or otherwise it would result in a deviant output as in (iiib) because clash deletion on the foot tier would cause stress shift on the superfoot tier: 
forward by Halle and Vergnaud (1987). Okazaki proposes a biplanar

(iii)
a. $\left(\begin{array}{lll}* & \ldots & .\end{array}\right)$
$(* \quad \ldots \quad$.
$\left(\begin{array}{lll}* & \ldots & .\end{array}\right)$
(*) $(*$. . $)$
$(*)(\ldots \quad$.
$(*)(\ldots \quad$.
$(*)(*).(*)$
$(*)(*).(*)$
$(*)(\ldots)(*)$
M MM M
M MM M
M MM M
$\mathrm{fæ}$ reld $+\mathrm{u} \rightarrow \mathrm{fæ}$ reld $+\mathrm{u} \rightarrow$ fæ reld $+\mathrm{u}$
(from the top down)

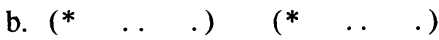
(*) $(* . \quad$.
(*) $\left(\ldots *^{*}\right)$
(*) $(*).(*)$
(*) $(.).(*)$
M MM M
M MM M
fæ $\quad$ reld $+\mathrm{u} \rightarrow *$ fæ reld $+\mathrm{u}$

(from the bottom up)

This top down application, however, does not hold for clash movement, for example, the Rhythm Rule in Present-day English, as can be illustrated with twenty-two Tennesee legislators $\rightarrow$ twenty-two Ténnesée législators below (we do not represent the mora tier below, since the language is syllable-counting):
(iv)
a. (. . . . . . *...)
$\left(. . . .{ }^{*}\right)(* . .$.
$\left(. \quad . *^{*}\right)\left(. \quad{ }^{*}\right)(*, .$.
$\left(*^{*}.\right)(*)(* \quad).(*)(*).(*$.
$\begin{array}{llllllllll}\sigma & \sigma & \sigma & \sigma & \sigma & \sigma & \sigma & \sigma & \sigma & \sigma\end{array}$
twenty-two Tennesee legislators

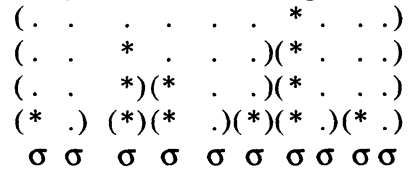

$\rightarrow$ twenty-two Tennesee legislators

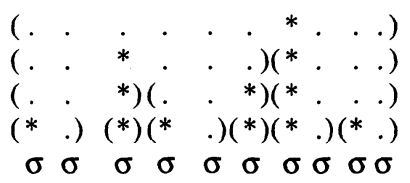

$\rightarrow$ twenty-two Tennesee legislators
(. . . . . . * . . )
$(. \quad . \quad * \quad . \quad).(* .$.
$\left(. \quad . *^{*}\right)\left(. \quad . *^{*}\right)(* .$.
$(* \quad).(*)(* \quad).(*)(*).(*$.
$\begin{array}{llllllllll}\sigma & \sigma & \sigma & \sigma & \sigma & \sigma & \sigma & \sigma & \sigma & \sigma\end{array}$

$\rightarrow$ *twenty-two Tennesee legislators

(from the top down)

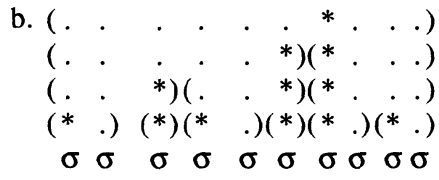

twenty-two Tennesee legislators

(. . . . . . * . .)

$\left(. . . *^{*} ..\right)(* . .$.

$\left(.{ }^{*}\right)(*$. . $)(*$. . . $)$

$\left(*^{*}.\right)\left(*^{*}\right)\left(*^{*}.\right)(*)\left(*^{*}.\right)(*$.

$\begin{array}{llllllllll}\sigma & \sigma & \sigma & \sigma & \sigma & \sigma & \sigma & \sigma & \sigma & \sigma\end{array}$

$\rightarrow$ twenty-two Tennesee legislators

(. . . . . . *...)

$(* . . . \quad . \quad).(* . .$.

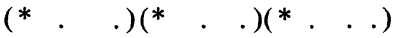

$\left(\begin{array}{ll}* & .\end{array}\right)(*)(* \quad).(*)(*).(*$.

$\begin{array}{lllllllll}\sigma & \sigma & \sigma & \sigma & \sigma & \sigma & \sigma & \sigma & \sigma\end{array}$

$\rightarrow$ twenty-two Tennesee legislators
(..........)

$(. . .5 . \quad . *)(* .$.

$(. \quad . \quad *)(* \quad . \quad).(* . .$.

$(* \quad).(*)(* \quad).(*)(*).(*$.

$\begin{array}{llllllllll}\sigma & \sigma & \sigma & \sigma & \sigma & \sigma & \sigma & \sigma & \sigma & \sigma\end{array}$

$\rightarrow$ twenty-two Tennesee legislators

(. . . . . . *...)

$\left(. . . *^{*},.\right)(* . .$.

$(* \quad . \quad).(* \quad).(* . .$.

$\left(*^{*}.\right)(*)(* \quad).(*)(*).(*$.

$\begin{array}{lllllllll}\sigma & \sigma & \sigma & \sigma & \sigma & \sigma & \sigma & \sigma & \sigma\end{array}$

$\rightarrow$ twenty-two Tennesee legislators

(from the bottom up) 
approach to Old English prosody in line with $\mathrm{K} \& \mathrm{O}$ : one for stress assignment and the other for stress deletion and high vowel deletion. The parameter settings on the stress plane are given in $(3 \mathrm{a})$, and the parameter settings on the deletion plane in $(3 b)$ :

( 3 ) a. Line 0 asterisks: rime head vowels. ${ }^{9}$

Line 0 parameter settings: [+ BND, + HT, left-headed, right-to-left].

Line 1 parameter settings: [- BND, + HT, left-headed].

b. Line 0 asterisks: rime head vowels.

Accent Rule: heavy syllables.

Line 0 parameter settings: [+ BND, + HT, right-headed, left-to-right].

The metrical constituents on the deletion plane in (3b) were first proposed by $\mathrm{K} \& \mathrm{O}$ to account for high vowel deletion, and in addition are utilized, Okazaki claims, to erase incorrectly-assigned stress on the stress plane, the erasure being formulated in (4): ${ }^{10}$

(4) Stress Deletion

*

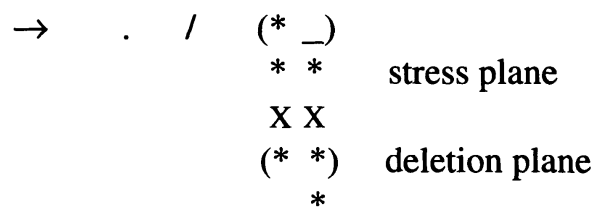

As examples of the mechanism of stress assignment and stress deletion, consider the following cases:

In either way, the Rhythm Rule is required to apply three times to this phrase. If it applied in a top down fashion, the second application would lead to a clashing configuration again, where the lower of the two ajacent grids would be moved to the original position (i.e. at the third application). Unfortunately, this would generate a wholly illformed pattern. If we adopt bottom up applications, however, we can obtain the correct result (after the first application of clash movement, the head of a superfoot shifts to the left to pursue its landing site). We do not have sufficient evidence, at the moment, to show whether top down applications iand bottom up applications are always true for clash deletion and clash movement, respectively.

9 BND and HT indicate "bounded" and "head-ternimal" constituents, respectively.

${ }^{10}$ In what follows, the constituents above the central line of segments are on the stress plane, and the ones below it are on the deletion plane. The latter constituents are employed not merely for stress deletion and high vowel deletion but for resolution which is discussed in section 3.2. 
( 5 )

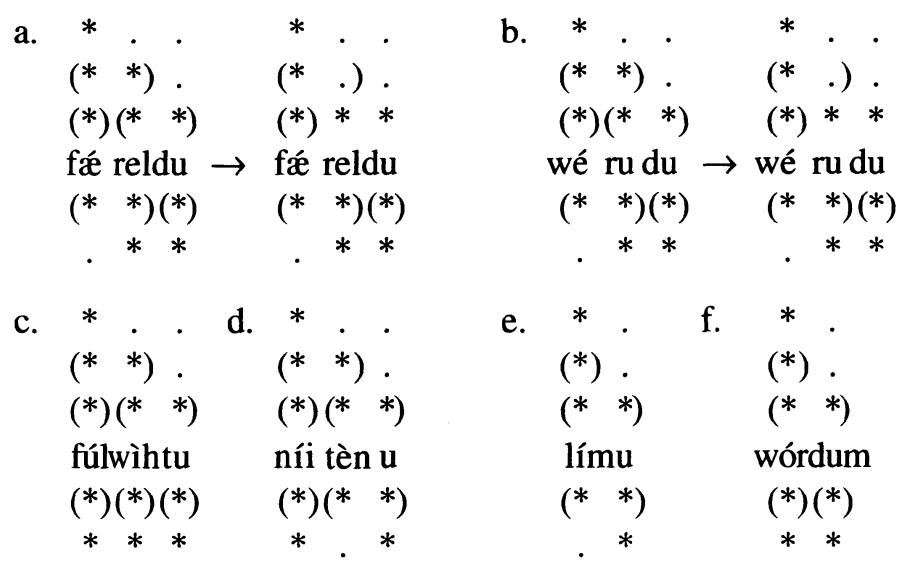

The fundamental differences of the above two approaches can be summarized in three respects. First, evidently, the former approach is uniplanar while the latter is biplanar. Second, the former considers Old English as mora-counting since all rime segments are stress-bearing, while the latter regards it as syllable-counting since only rime head vowels are stressbearing. Finally, in the former any two adjacent stresses are defined as a clash and undergo clash deletion, whereas in the latter two adjacent stresses are not necessarily defined as a clash and hence do not undergo stress deletion, but are defined as such only in a highly-restricted environment such as the one in (4). These differences, furthermore, bring about theoretical and empirical differences which will turn out to be crucial in light of various types of data, particularly the exceptional cases mentioned earlier and segmental processes such as high vowel deletion, resolution, Sievers's Law, and West Germanic gemination. In the following sections, we will examine these phenomena and search for a better way to account for them in both theoretical and empirical respects.

\section{Extraordinary Stress on Certain Suffixes}

There are some peculiar suffixes in Old English which always attract stress on themselves; thus, when these suffixes appear on the final syllable of a word without inflectional endings, secondary stress falls on the ultima-precisely the exceptional cases pointed out in the previous section (i.e. type (b)). Suffixes of this type are listed in (6) (Okazaki (1989)):

( 6 ) -doom, -cund, -fæst, -weard, -full, -had, -laac, etc. 
Their stress-attracting nature seems to be attributed to the fact that these suffixes have a good deal of wordhood and produce a pseudo-compound by attaching to another word.

Formally, we assume that the suffixes listed in (6) attract the head of a superfoot and trigger stress movement as exemplified in (7):

( 7 )
a. $(*$
$(*$. . . .)
$(* . \quad . \quad$.
$(*).(* \quad .$.
$(*).(. \quad *$.
$(*)(* \quad .$.
$(*).(*)(*$.
$(*).(*)(*$.
$(*)(*)(*$.
MM M MM
MM M MM
MM M MM
wíi tè +laac $\rightarrow$ wíi te +làac cf. hán gòd+es
b. $\left(\begin{array}{lllllllll}* & \ldots & \ldots & (* . & \ldots & \ldots & (* & & \end{array}\right.$
$(*).(* . \quad) \quad.(*).\left(. . *^{*}\right) \quad(*).(* . \quad$.
MM MM MM MM MM MM MM MM MM
ín nàn+weard $\rightarrow$ ín nan+wèard cf. hláa fòrd+es
$(*).(*).(*) \quad.(*).(*).(*) \quad.(*).(*).(*$.

Inflectional endings, needless to say, do not trigger stress movement, as in the case of hangodes and hlaafordes, because they have no noticeable wordhood. Other cases of rightward movement in which morphemes with prominent wordhood attract stress are documented in German, a cognate language of Old English (the data are taken from Kiparsky (1973)):
( 8 )
a. $(*$
$(*)(* \quad . \quad)$
$(* \quad .$.
b. $(* \quad$.
$(* \quad . \quad$.
$(*)(*)(*$.
$(*)(. \quad *$.
$(*)(* \quad$.
$(*)($.
$(*)(*) \quad(*)$
$(*)(*)$
$(*)(*)(*$.

ún sìchtbar $\rightarrow$ ún sichtbàr

The words in (7) and (8) are somewhat different from each other in their morphemic structures, but are just the same in that the word-final morphemes (i.e. vater 'father' and -bar '-able') have some wordhood and can be the landing site of rightward stress movement.

It is crucial that stress movement is ordered before clash deletion observed in (2), or otherwise the landing site of stress movement might be erased in advance by clash deletion. In (7a), after stress movement, the head over $t e$ is deleted by clash deletion; or if they applied in reverse order, the head over laac would be deleted by clash deletion and stress movement could not occur. This ordering relation (i.e. stress movement before clash deletion) is also observed in Halle and Vergnaud's (1987) and Haraguchi's (1991) analysis of Present-day English. For example, the derivation of elementary proceeds as follows: 
(9)

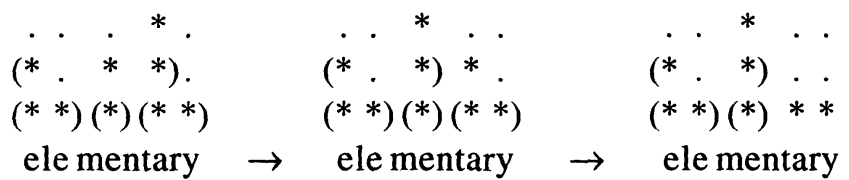

Although stress movement is leftward in this case, the landing site of the primary stress (i.e. the stress on men) would be lost if clash deletion were ordered before stress movement: such ordering would result in a deviant output like *èlementáry. Again, note here that stress movement is allowed to apply due to the wordhood of element.

To sum up, the landing site of stress movement should be a morpheme with some wordhood irrespective of whether the movement is triggered by a stress clash (e.g. (8)) or some morphological force (e.g. (7) and (9)). Other analyses of the words in (7), however, might also appear to be possible that do not postulate stress movement. One such analysis is proposed by Okazaki (1989), who assumes that the morphemes given in (6) constitute their own stress domain and that foot construction should not cross the boundaries of the stems and the morphemes specified. In other words, in our analysis any morpheme constitutes a domain of foot construction and the morphemes in (6), moreover, trigger stress movement, while in Okazaki's only the morphemes in (6) constutute a domain of foot construction. The words in question, then, have the following metrical structures according to the parameter values in (3) and the stipulation above:

(10)

a.

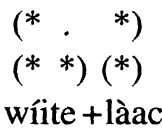

b.

$$
\begin{aligned}
& \left(* \quad *^{*}\right) \\
& \left(\begin{array}{lll}
* & *
\end{array}\right) \\
& \text { ínnan +wèard }
\end{aligned}
$$

This solution might at first appear to be attractive because providing these suffixes with their own stress domain amounts to assigning stress to them constantly, as is the case with Present-day English suffixes such as -ary, -ory, -ative, and the like. ${ }^{11}$ The situation, however, becomes difficult when we take into consideration the fact that when the suffixes concerned are preceded by monosyllabic morphemes, they have secondary stress only if followed by an inflectional ending (e.g. wisdòme); otherwise, they do not

${ }^{11}$ This analysis of ary-type suffixes is proposed by Halle and Vergnaud (1987). Although these suffixes always bear stress, their stress undergoes clash deletion when followed immediately by main stress, as was seen in (9). 
(e.g. wisdom). Okazaki's analysis, as it stands, does not account for the stress contrast of this minimal pair, since the word in (11b) actually does not have seconary stress on the ultima:

(11)

$\begin{array}{ccc}* & \cdot & . \\ (* & *) & . \\ (*) & (* & *)\end{array}$

wís + dòme b. * .

$(* \quad *)$

$(*) \quad(*)$

*wís+dòm

He then proposes the following patch-up method to avoid the difficulty above:

(12) Condition on Stress Deletion

The morphems in (6) undergo stress deletion only if they are not followed by any inflectional ending.

Thus, the cases in (10), though not followed by any inflectional ending, do not undergo stress deletion, since they have no clashing configuration; neither does the word in (11a), since it has an infletional ending; and stress deletion does apply to the word in (11b) since it has a clash and is not followed by any inflectional ending.

The analysis truly seems to give a tactful answer to the difficulties with the suffixes in (6). However, we have to say that the solution is on the horns of a dilemma and suffers from some inadequacies in empirical and theoretical respects. The fundamental cause for the dilemma lies in the fact that Okazaki utilizes two metrical planes.

First, in our framework any two adjacent stresses are defined as a clash, whereas in his approach only two adjacent stresses which head a binary constituent on the deletion plane (i.e. the environment of stress deletion (4)) are so defined. It is obvious that the former definition is theoretically favorable, because it is consistent with the way a clash is defined in languages other than Old English (cf. Tanaka (1992a, c) among others). In other words, defining a clashing configuration universally is preferable to defining it language-specifically. In fact, it is worth noting that if two adjacent stresses that do not head a binary constituent on the deletion plane (e.g. metrical structures such as (5c) and (5d)) were not a clash, the configuration would violate the Principle of Rhythmic Alternation, a universal principle proposed by Selkirk (1984).

Second, consequently, the applicability of our clash deletion is determined universally: it deletes the lower grid of the two adjacent stresses. However, the applicability of stress deletion (4) is language-specific: it deletes the grid on the basis of the information on the deletion plane. 
Again, our clash deletion has a theoretical advantage, since in all languages with secondary stress, the grid to be deleted is the lower one.

Third, to account for the exceptional nature of the suffixes in (6), our approach has only to assume that they trigger stress movement, while Okazaki has to employ two assumptions, namely, the domainhood of the suffixes and the condition in (12). From a conceptual point of view, we should attempt to explain a fact with as few devices as possible.

Fourth, we in fact doubt the validity of condition (12), since this type of condition, which stipulates the applicability of stress deletion on the basis of inflectional morphology, does not seem to be attested in other languages, and for that matter, it is wholly unclear why the applicability of stress deletion is determined by the presence or absence of an inflectional ending, since there seems to be no principled reason for the relationship between the two. Even if we put aside the question as to the relation between metrical operation and inflectional morphology, there is another serious problem with the adequacy of the condition in (12). Although he claims that the condition makes it possible to delete stress in (11b) and not to delete stress in (11a), stress deletion (4) in fact would not apply to cases such as (11b) because their metrical structures on the deletion plane do not match up to the environment of the rule, hence erroneous outputs are generated as shown in (13):

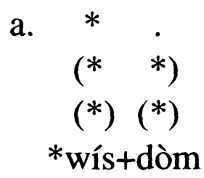

$(*)(*)$ b. *

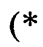

$(*)$

*áag+làac

(*) $\quad(*)$ c. *

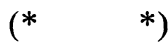

$(*) \quad(*)$

*éorð+wèard

$(*)$

$(*)$

*

All the words above do not have secondary stress on their final syllable. One solution to escape from this difficulty might be to revise the definition of a stress clash: any two adjacent stresses on the stress plane. However, if this were the case, secondary stress would be incorrectly erased in cases like (5c), (5d), and (11a). On the other hand, if only two adjacent stresses that head a binary constituent on the deletion plane were considered to be a clash, secondary stress would incorrectly not be erased in (13).

We thus have to conclude that Okazaki's approach is on the horns of a dilemma and that the dilemma results from his utilizing two metrical planes. The use of two metrical planes in turn results in the languagespecific definition of a stress clash, language-particular stress deletion (4), 
the domainhood of the suffixes concerned, condition (12), or all of the problems mentioned above. To put it differently, assuming two metrical planes in Old English seems to be redundant, or in fact defective.

In contrast, our analysis allows us to account for the stress contrast in (11) and to generate the correct outputs straightforwardly:
a. $(* .,$.
$(*).(* \quad$.
$(*).(*)($.
MM M M
b. $(*$. . .)
$(*$. . .)
(*.) (*.)
MM MM
wís+dòm+e
wís+dom

Stress movement does not occur in (14a), since a mere inflectional ending does not attract stress. The final syllable of (14a) loses the head of the foot by clash deletion. (13b) and (13c) have the same prosodic structures as (14b).

Another possible approach to the suffixes in (6) might be to assume that they are provided with an accent underlyingly. ${ }^{12}$ If so, they invariably have secondary stress even when they are located at the final position of a word. Unfortunately, however, this approach has just the same effects as Okazaki's, and suffers from the same four problems above as long as it assumes two metrical planes.

The arguments so far demonstrate that a uniplanar approach is explanatorily superior to a biplanar one. From this we cannot necessarily conclude that a mora-based analysis such as ours is superior to a syllable-based analysis such as Okazaki's. One might ask, then, whether some uniplanar syllable-based analysis is possible. We suggest, however, that the answer to this question is probably negative, since a uniplanar account depends crucially on the assumption that Old English is a mora-counting language. Conversely, assuming Old English to be syllable-counting inevitably leads us to conclude, as do Okazaki and $\mathrm{K} \& \mathrm{O}$, that the language has two metrical planes. It thus follows from the above discussion of stress facts that Old English has one and only one metrical plane and is also moracounting. In the following sections, we will adduce further evidence showing that the language is mora-counting. The evidence derives from high vowel deletion, resolution, Sievers's Law, and West Germanic gemination.

\footnotetext{
12 Technically, an underlying accent is assigned by the Accent Rule in the framework of Halle and Vergnaud (1987).
} 
3. Further Issues in Old English and Other Early Germanic Prosody

\subsection{High Vowel Deletion}

It is generally known that a high vowel in an open syllable is deleted in Old English when preceded by CVC, CVV, or CVCV. Thus, deletion occurs in $(15 a-c)$, but not in $(15 d-f)$, where each high vowel is preceded solely by $\mathrm{CV}$ or closed by a consonant: ${ }^{13}$
(15)
a. færeldu
b. werudu
c. fulwihtu
$\varnothing$
$\emptyset$
d. niitenu
e. $\operatorname{limu}$
f. wordum

Our account of this contrast is straightforward. We propose that high vowel deletion is formulated in the manner below:

(16)

$(*)$

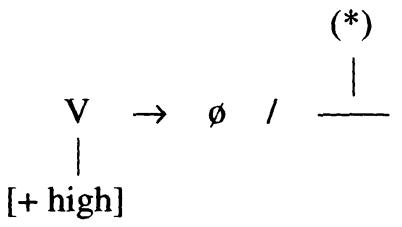

The rule states that a high vowel is deleted when associated with a degenerate foot with its own genuine head. As is clear from (2), (16) does apply to the vowels in $(15 \mathrm{a}-\mathrm{c})$ because they are actually dominated by a degenerate foot $(*)$, whereas it does not to the vowels in $(15 \mathrm{~d}-\mathrm{f})$ because they are dominated either by a headless degenarate foot (.) or by a binary foot $\left(^{*}\right.$.). The fact that only vowels with $\left(^{*}\right)$ undergo deletion is related to the defectiveness of the foot: (.) is also defective, but vowels with the headless degenerate foot undergo vowel reduction (cf. Kaminashi (1989) and Tanaka (1991b)), and $(*$.) is perfect and self-contained. That is why high vowel deletion holds true only for vowels dominated by $\left(^{*}\right)$. The vowels to be deleted, of course, have no secondary stress or no head of a superfoot (for optional deletion of vowels with secondary stress, see footnote 15).

In contrast, Okazaki adopts $\mathrm{K} \&$ O's version of high vowel deletion given in (17):

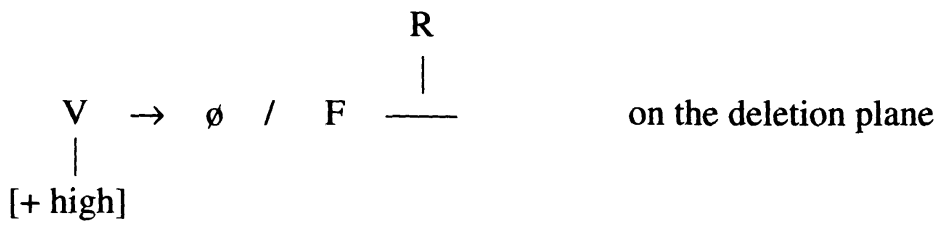

13 The facts with which we are concerned in this section are based on the description of the Mercian dialect of the Vespasian Psalter. The data are taken mainly from D \& L. 
That is, a high vowel is deleted when it is preceded immediately by a foot on the deletion plane and the rime node dominating it does not branch. Hence, in light of the metrical structures shown in (5), (17) does apply to $(15 \mathrm{a}-\mathrm{c})$ because either a binary or a unary foot immediately precedes the vowels in question, but it does not apply to $(15 \mathrm{~d}-\mathrm{f})$ because they are not preceded immediately by a foot or are dominated by a branching rime node.

This formulation indeed has shed new light on the development of metrical theory: it has proved to be capable of capturing uniformly a segmental rule which had been considered to apply after any of CVC, CVV, and CVCV; that is, after a foot. As Tanaka (1991b) points out, however, there seem to be some problems with the formulation that still remain to be resolved.

First, the applicability of the rule relies decisively not only on access to foot structures but on access to syllable structures, in particular, rime branchingness. A segmental formulation, such as that of Dresher (1978) must also refer to rime branchingness, and (17) still preserves a descriptive relic which may be dispensed with given theoretical advances. Our formulation (16) does not have to access to rime branchingness but only to foot structures, because a high vowel with a branching rime node is always dominated by a binary foot. The rule, therefore, is correctly predicted to be unapplicable to a high vowel with a branching rime node, as seen in (15f).

Second, (17) does not provide a principled account of why high vowel deletion applies to a vowel after a foot at all; in other words, why is it that the target of the rule (i.e. a high vowel) should be situated at a position apart from the trigger (i.e. a foot)? The formulation seems to be entirely non-local in nature. Generally, it can be said that there are two types of locality in the relation between the target and the trigger of a rule: horizontal locality (adjacency) and vertical locality (dominance). Our formulated clash deletion, for example, is local because the target is adjacent to the trigger on a prosodic tier. This is also the case with (16) because the target is dominated by the trigger. (17), however, has no locality in the sense above; that is, the target is not only non-adjacent to the trigger on the same prosodic tier but also not dominated by the trigger (for details of the Locality Condition, see Tanaka (1992c)).

Third, the most serious drawback of (17) is that there arise several cases where it applies two times erroneously. For instance, $\mathrm{K} \& \mathrm{O}$ remark that the penultimate and the ultimate vowels of /haaligu/ 'holy' and /heeafudu/ 'height' are retained, the outputs being [haaligu] and [heeafudu]; however, 
(17), as it stands, would generate *[haalg] and *[heeafd]:

(18)

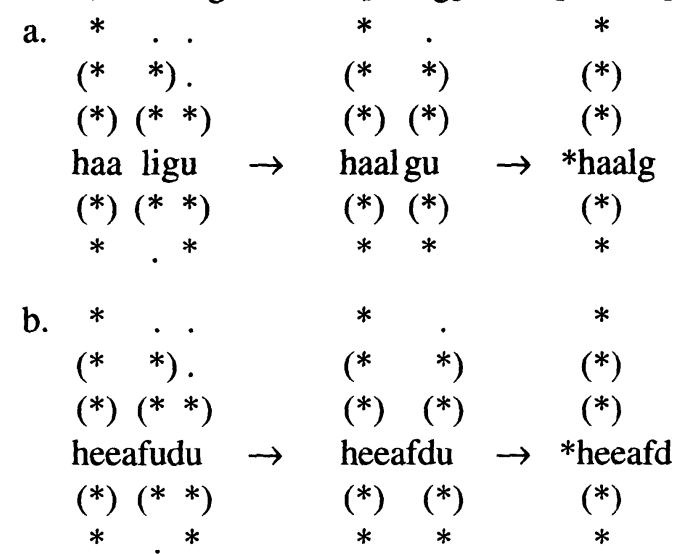

After the first application, the final high vowel is still preceded immediately by a foot on the deletion plane, hence it would apply once more deriving deviant results. ${ }^{14}$ The same criticism also holds true for Kaminashi's (1989) formulation of high vowel deletion, as Yokotani (1991) points out.

Finally, Okazaki's proposed stress system as a whole produces some illformed stress patterns since (17) would derive *[háalgès] and *[héeafdès] from /haaliges/ and /heeafudes/, respectively:

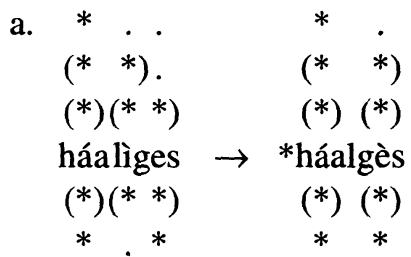
b. $(* \quad *) . \quad(* \quad *)$ $(*)(* *)$ héeafùdes $\rightarrow *$ héeafdès $(*)(* *)$ $(*) \quad(*)$ In either case, the stress rules in (3) and high vowel deletion (17) would locate secondary stress on the final syllable although there is actually no secondary stress there. Unfortunately, stress deletion (4) does not erase it because the ultima does not head a bianry foot on the deletion plane. Again, this fact seems to show that Okazaki's approach is on the horns of a

\footnotetext{
${ }^{14}$ A possible way to patch up the state of affairs would be to encode the statement that rule (17) does not apply to a vowel with secondary stress. Rule (17) would then be more complicated because it should have access to metrical structure on the stress plane as well as rime branchingness and metrical structure on the deletion plane. Still worse, such a stipulation would not account for the data in (19), where high vowels with secondary stress can be deleted.
} 
dilemma: if any two adjacent stresses were a clash and the erroneouslyassigned stress above were erased, the erasure would have excessive power to delete secondary stress in (5c), (5d), and (11a); but if he adhered to stress deletion (4), such cases as (13) and (19) would not be accounted for.

Our proposed system, in conjunction with (16), can give an account of the latter two problems. Consider the following derivations:

(20)

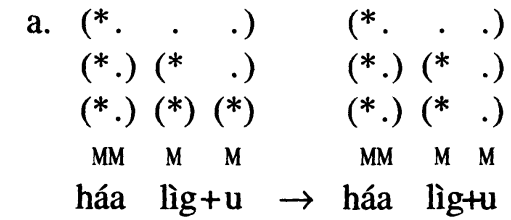

b.

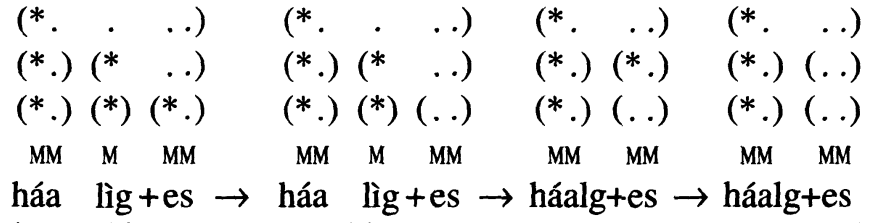

In (20a), resolution, which is discussed in section 3.2. below, prevents rule (16) from applying; thus, the resulting form is a non-deleted one [haaligu]. In (20b), after clash deletion, rule (16) may apply to the penultimate vowel since the vowel is dominated by $(*)$, although secondary stress (i.e. the head of a superfoot) is located on the vowel to be deleted as compared to ordinary cases such as $(2 a-c)$ without secondary stress. ${ }^{15}$ Applying the rule shifts the head of a superfoot rightward; however, the landing site of the shifted head does not have any grid on the foot level, so that it is erased by

${ }^{15}$ More strictly, forms with $\mathrm{CVVCHCH}, \mathrm{H}$ a high vowel, such as haaligu and heea$f u d u$ have more opaque paradigms with respect to high vowel deletion than they appear to be the case. Taking the paradigm of haaligu as an example, the forms in (va) always retain their high vowels, hence high vowel deletion does not apply; but in (vb), either deleled or retained versions are acceptable; and the words in (vc) can also undergo deletion in spite of the fact that their segmental material is much the same as that of haaligu, which is the (va) type (the data are documented in Okazaki (1987)):

(v) a. haaligu, haaligra, haaligre, etc.

b. haaliges, haaligum, haaligan, etc.

c. haalige, haaliga, etc.

The non-application of rule (16) to the (va) forms is accounted for in relation to (20a); as stated in footnote 18 , the $g$ of the latter two words in (va) is syllabified into the following onset because we support an "onset max" approach, so that the explanation made in (20a) is true for the words as well. The optional nature of deletion in (vb) is probably due to the fact that the vowel concerned is dominated by the head of a superfoot, or sec- 
convention. In either example, resolution or clash deletion plays a crucial role here: it determines not only the presence or absence of secondary stress but the application or non-application of high vowel deletion.

Again, the arguments we have made thus far support our uniplanar account, and consequently, our mora-based approach.

\subsection{Resolution}

Phonologists studying Old English have agreed that CVV, CVC, and CVCV constitute a class with regard to the description of some phonological processes; that is, in the language, two light syllables behave equivalently to a heavy syllable in specifying the environments of such phenomena. As D \& L observe, among the processes are high vowel deletion and Sievers's Law. This segmental class has been considered to participate crucially in the description of metrical resolution as well. (21a) exempifies a well-formed metrical pattern in the verses of Beowulf, which Sievers (1893) calls Type E, while (21b), (21b') and (21c) deviate from the pattern (D \& L):

(21) a.

$$
\begin{aligned}
& \text { sínc-fàagễ / sél } \\
& \text { b. 'hall shining with treasure' } \\
& \text { b'. héal-ðègnềs / héte 'the hall-thane's hatred' } \\
& \text { * héal-ðègnềs / hétêx } \\
& \text { c. *príist-hỳydìn / píiodễn 'bold prince' }
\end{aligned}
$$

ondary stress (cf. (20b)). In ordinary cases, where a high vowel does not bear secondary stress as in $(2 a-c)$, rule (16) obligatorily applies because of the weakness of the vowel while in the forms with secondary stress, the application of rule (16) becomes optional for the very reason of the vowel strength. Finally, as for (vc), we assume that the ultimate vowel is long underlyingly, and hence it has two moras as illustrated below:

$$
\begin{aligned}
& \text { (vi) }(* . . . .) \\
& (* .)(* \ldots) \\
& (* .)(*)(* .) \\
& \text { MM M MM } \\
& \text { haa lig+e }
\end{aligned}
$$

The words in (vc), then, obtain the same prosodic structures as the words in (20b) or (vb), which match up to the precise envorinment of rule (16). 
In the second half of each verse, (21a) consists of one heavy syllable, and the others of two light or two heavy syllables, respectively. (21b), however, does occur as well as (21a), a fact that is traditionally explained by saying that the two light syllables in (21b) are "resolved", which means they are treated as a single heavy syllable.

Our account of these phenomena is straightforward. We propose that resolution is formulated in the following way:

$$
(*)(*) \rightarrow(* .)
$$

The rule is assumed to be ordered before clash deletion, and therefore the following examples are actually immune to clash deletion, contra (2), but undergo resolution (22):

$$
\begin{aligned}
& \text { a. }(* \\
& (* .)(* \quad .) \\
& \text { (*. . .) } \\
& (* .)(* .) \\
& (*)\left({ }^{*}\right)(*) \\
& (*)(* .) \\
& \text { MM M M } \\
& \text { MM M M } \\
& \text { níi tèn+u } \rightarrow \text { níi tènu }
\end{aligned}
$$
b. $\left(\begin{array}{lll}* & .\end{array}\right)\left(\begin{array}{ll}* & .\end{array}\right)$
$\left(\begin{array}{lll}* & .\end{array}\right)\left(\begin{array}{ll}* & .\end{array}\right)$
$(*)(*)\left(\begin{array}{ll}* & .\end{array}\right)$
M M M M
$\lim +\mathrm{u} \rightarrow \operatorname{lím} \mathrm{u}$

Given (22), both sél and héte have a single binary foot whereas hétê and píiodén each have two feet as shown below:
a. $(* . \quad . \quad).(*$.
b. $(* . \quad \ldots \quad \ldots)(*$.
$(*).(* . \quad).(*$.
$(*).(*).(*)(*$.
$(*).(* . \quad).(*$.
MM MM M MM
$(*).(*).(*).(*$.
sínc-fàa gễ / sél
MM MM MM M M
héal-đèg nễs / héte
b.' $(* . \quad . . \quad \ldots)(* \quad$.
$(*).(* . \quad .).(* \quad$.
$(*).(*).(*).(*)(*)$
MM MM MM M M
héal-ðèg nễs / hé tề
c. $(*$. $\quad$.. . . $)(*$. . .)
$(*).(* . \quad).(* . \quad .$.
$(*) \quad.(*).(*).(*).(*$.
MM MM MM MM MM
príist -hỳy dî̀g/ píiodèn

When resolution (22) applies to héte in (24b), which is assigned two feet by our proposed stress system, the very output is héte, with a single binary foot. Thus, the illegalness of (24b') and (24c) is attributed to the presence of two feet in the second half. Conversely, the two light syllables héte can be treated as a heavy syllable sél because they both are provided with a single binary foot. We are thus led to conclude that a legal pattern of a Type E verse of Beowulf has three feet in the first half and a single foot in the second half.

In Okazaki's stress system, the contrast will not be computed by his 
syllable-counting feet, because the relevant distinction will be made not between $(25 a, b)$ and $\left(25 b^{\prime}, c\right)$ but between $(25 a)$ and $(25 b-c)$ :
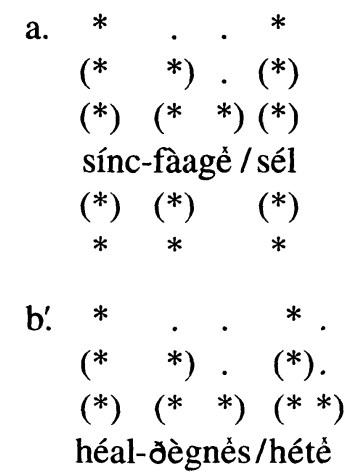

b.

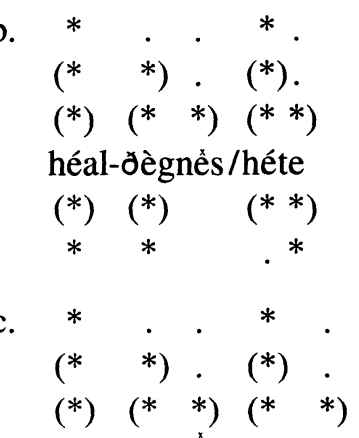

príist-hỳydìg / píiodên

$(*) \quad(*)(*)(*)(*)$

$* \quad * * * *$

Note here that sél is given a degenerate foot while héte, hétê, and piiodên are provided with a binary foot because his foot construction is based on syllable counting; hence, Okazaki's proposed feet do not predict (25a) and, particularly (25b), to be legal as a Type E metrical pattern. The problem might appear to be somewhat alleviated if the possibility of resolution would be computed on the basis of the feet on the deletion plane: piioden is assigned two feet but the others a single foot. Unfortunately, then, the distinction in well-formedness between sél and héte on one hand, and hété on the other, could not be captured since all of these are given the same number of feet.

Again, we conclude that an adequate theory of Old English prosody must utilize not syllabic but moraic feet. And moraic feet, in turn, allow us to analyze the prosody in uniplanar fashion.

\subsection{Sievers's Law}

As D \& L demonstrated, metrical structures also play a role in accounting for Sievers's Law, which had been considered to be a mere vocalization rule triggered by certain segmental structures. Since the effect of the rule is obscured in Old English, let us look at data from Gothic, a language which has basically the same stress patterns and hence the same metrical structures as Old English. In segmental terms, this rule turns / $\mathrm{j} /$ into [i] when preceded immediately by a tautosyllabic onset consonant and by any of CVV, CVC, CVCV, and CVCCV. Observe the following sample forms 
from the second person singular indicative of class I weak verbs:

(26)
a. /sookjis/
[sookiis]
'seek'
b. /namnjis/ $\rightarrow$
[namniis]
'name'
c. /mikiljis/ $\rightarrow$
[mikiliis]
'glorify'
d. /glitmunjis/ $\rightarrow$
[glitmuniis]
'glitter'
e. /nasjis/ [nasjis]
'save'
f. /stoojis/
[stoojis]
'judge'

Sievers's Law applies in (26a-d) since its structural description is met, while it does not in $(26 \mathrm{e}, \mathrm{f})$ either because the glide in question is preceded by a single light syllable or because it is not preceded by a tautosyllabic onset consonant.

We construe the above $j-i$ alternation as a vocalization process or, more strictly, a process associating $/ \mathrm{j} /$ with a mora, and formulate it as in (27):

(27)

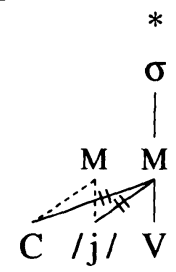

Restated informally, this rule associates $/ \mathrm{j} /$ with a mora if it is preceded by a tautosyllabic onset consonant and followed by a tautosyllabic vowel with the head of a foot, so that $/ \mathrm{j} /$ becomes [i]. If so, the contrast between $(26 a-d)$ and $(26 e, f)$ is easy to capture in terms of our prosodic structures:

a. $(*$. ..)

(*. ..)

$(*).(*$.

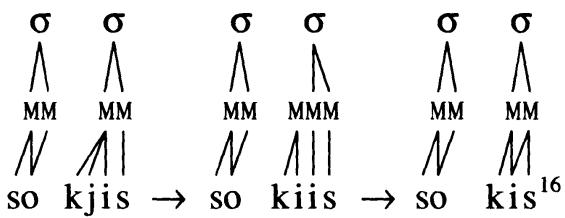

${ }^{16}$ At the last stage in $(28 a, b)$, the inserted mora is incorporated into the following syllable because the phonemic inventory of Gothic contains the long vowel $i$ i. (i.e. $i$ is a possible long vowel of Gothic). The two $i$ 's, then, merges into a single featural unit $i$, 
b. $(* . \quad . \quad \ldots)(* . \quad .$.

$(*).\left(. *^{*}\right) \quad(*).\left(. *^{*}\right)$

$(*).(*)(*) \quad.(*).().(*$.
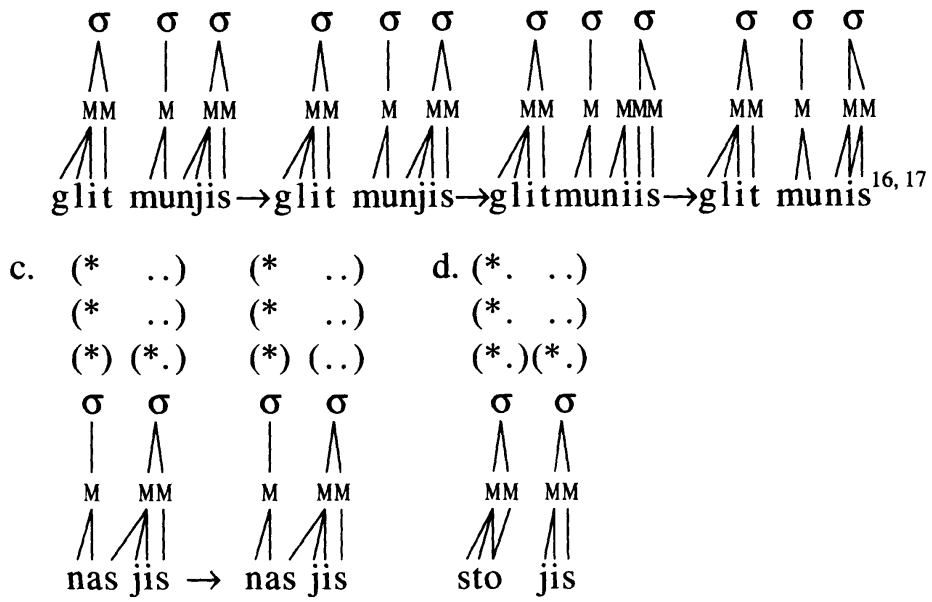

which is associated with two moras. Finally, the final mora is erased by an independent requirement on syllable structure to the effect that more than two moras are not licensed per syllable, so that the final segment $s$ is associated with the preceding mora by stray adjunction. What we have just stated can be shown as in (vii):

(vii)
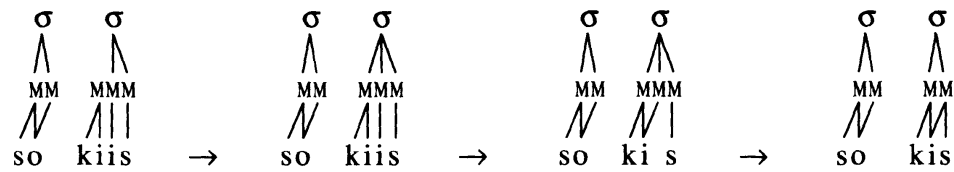

${ }^{17}$ We assume that the word-final morpheme is attracts the head of a superfoot, as was the case with the sufixes in (6). The assumption seems to be crucial in the case of glitmunjis:

(viii)
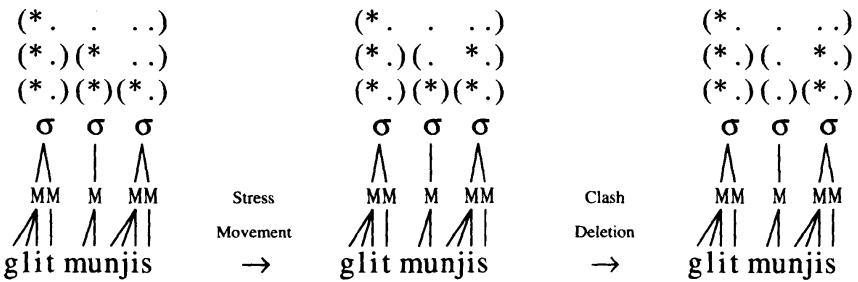

The final stage contains that configuration which triggers the application of vocalization, but if stress movement did not occur, clash deletion might delete the grid over jis and vocalization might not occur, either. 
Vocalization (27) does apply to $(28 \mathrm{a}, \mathrm{b})$ because the envorinments match up to the structural description, whereas it does not apply to the latter two cases because the head of the foot concerned is deleted by clash deletion in (28c) and the glide is not preceded by a tautosyllabic onset consonant in (28d).

Foot structures based on syllble-counting, however, would not predict what environment triggers vocalization, as is clear from the following instances:

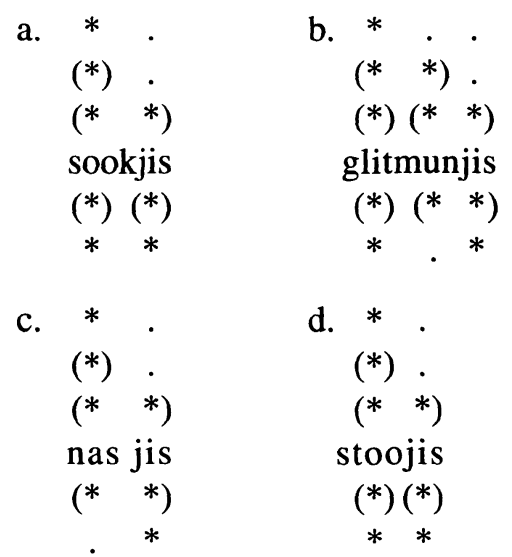

On the stress plane, $/ \mathrm{j} /$ occupies foot-internal position in all the examples whereas on the deletion plane, it occupies foot-initial position in (29a) and (29d), and foot-internal position in (29b) and (29c). So, it follows that no distinction would be made between $(29 a, b)$ and $(29 c)$ and that vocalization could not be formulated on the basis of metrical structures. A possible alternative would be to adopt a conventional account in terms of segment or syllable structures, but it would then bring about other problems as D \& L point out.

\subsection{West Germanic Gemination}

The final evidence for our approach involves facts around West Germanic gemination in relation to Sievers's Law and high vowel deletion. The former rule geminates consonants except $r$ when they are followed by a glide and preceded by a stressed light syllable. Sample forms are given below (the data are taken from Lahiri and Hulst (1987)):
a. /bedje/
$\rightarrow$
[bedde]
b. /bedjes/
$\rightarrow$
[beddes] 

c. /wiitje/
$\rightarrow$
[wiite]
d. /wiitjes/
[wiites]

If we assign stress to the words in (30) in accordance with our parameter settings, the environment of gemination will be clear from the metrical structures (the representations are after clash deletion):
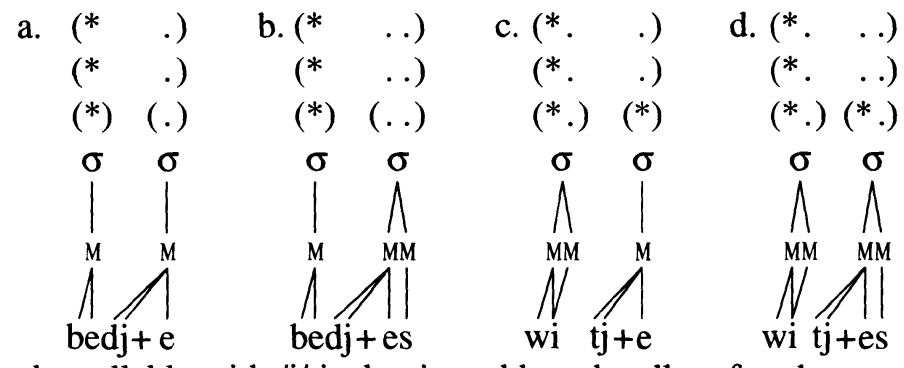

In (31a, $b)$, the syllable with $/ j /$ is dominated by a headless foot because of clash deletion whereas in $(31 \mathrm{c}, \mathrm{d})$, it is dominated by an ordinary foot. West Germanic gemination hence will be formulated so that [j] can totally assimilate to the preceding consonant when it is dominated by a headless foot (a root node is depicted as $\mathrm{R}$ below):

(32)

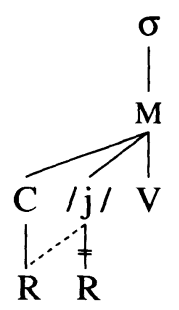

This rule is in complementary distribution with vocalization (27), which changes $/ \mathrm{j} /$ into [i] when dominated by $*$ (hence, the words in $(31 \mathrm{c}, \mathrm{d}$ ) undergo (27) and, moreover, (16)). ${ }^{18}$

Interestingly, this formulation makes it possible to account for rather complicated cases such as the minimal pair of cynn 'kind' and stycicu 'piece'. Although the two forms apparently contain stems with the same segmental material (i.e. (C)CVCC), the nominative plural marker $u$ surfaces only in the latter noun. We assume that their underlying forms are

${ }^{18}$ An anonymous $E L$ reviewer points out that if the $\mathrm{C}$ of $\mathrm{Cj}$ (e.g. $d$ or $t$ in (31)) is syllabified into the preceding coda, we can substitute gemination and $j$-deleton for West Germanic gemination (32): 
$/ c y n+j+u /$ and $/ s t y c \dot{c}+j+u /$, respectively, and further that West Germanic gemination (32) is ordered before vocalization (27) and high vowel deletion (16). The derivation of cynn and stycicu then proceeds as in (33):

(ix)
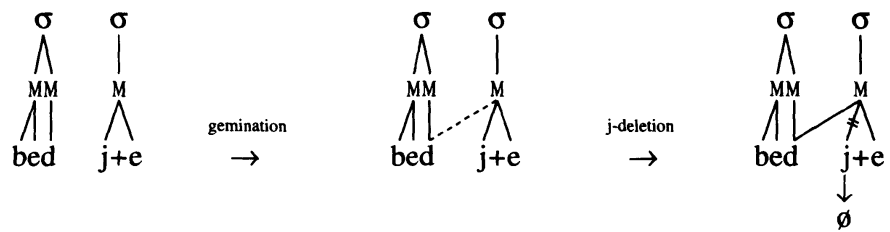

There seem to be, however, several arguments against an analysis utilizing the two rules, or a "coda max" approach.

First, if we adopted the coda max approach, the non-application of the two rules to $(31 \mathrm{c}, \mathrm{d})$ would not be predicted because the prosodic structures of bedje and wiitje would be just the same:
(x) a. $(*$. .)
$(* . \quad$.
b. $(*$. .)
$(* . \quad$.
$(*).(*)$
$(*).(*)$
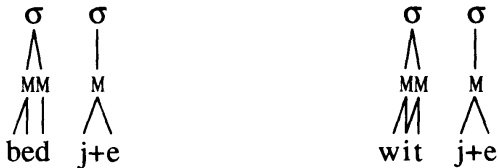

Indeed, if we formulated the rules in non-prosodic or segmental terms, their environments would have to be stated as "gemination applies after a short vowel and $j$-deletion applies after a geminate consonant." It is unfortunate, however, that this approach would not predict the contrast observed in (33); in fact, in the case of styc̈u, the two rules together with vocalization (27) and high vowel deletion (16) would derive an unattested form * stycic:

(xi) a. $/ \mathrm{cyn}+\mathrm{j}+\mathrm{u} /$
$\mathbf{n}$
cynnju
$\varnothing$
cynnu
-
cynnu
$\varnothing$
cynn

b. /sty $\ddot{c} \dot{c}+j+u /$

$\begin{array}{cl}- & \text { gemination } \\ \text { styciju } & \\ \text { styciu } & j \text {-deletion } \\ \text { styciu } & \text { vocalization (27) } \\ \varnothing & \text { high vowel deletion (16) } \\ \text { * styci } & \end{array}$

Second, the facts concerning Sievers's Law cannot be captured correctly, provided that coda max syllabification would also be applicable to early Germanic languages other than Old English, such as Gothic. Recall that (xiib) and (xiic) do not undergo vocalization. Their prosodic structures, however, would be equivalent to (xiia) to which vocalization does apply: 
(33)
a. $/ c y n+j+u /$
b. /styc̈ $+j+u /$
$\mathrm{n}$
cynnu
cynnu
$\emptyset$
cynn
WGmc gemination (32) styc̈cju
i vocalization (27)
styçiu
$\emptyset$
styc̈u
high vowel deletion (16)

Gemination applies to the form in (33a) only, because the final syllable loses the head of a foot by clash deletion, which is a necessary condition for the application of gemination; on the other hand, vocalization applies to the form in (33b) because of the presence of the foot head; and now that both of the nouns begin with a heavy syllable which is immediately followed by a high vowel, the vowel is deleted by (16).

There are three crucial points here. First, the initial syllable of the under-

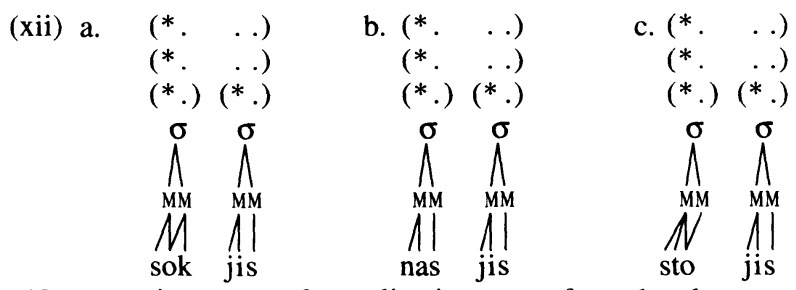

Even if the environment of vocalization were formulated segmentally as $\mathrm{CVVC}_{-}$, it would erroneously fail to apply to examples such as mikiljis and glitmunjis (see section 3.3.).

Third, the suggested analysis should allow the $C$ of the $C j$ sequence to occur in the onset position as well as in the coda position, since Old English stycicju in (33b) or (xib) and Gothic namnjis in (26b) are syllabified as styc.cju and nam.njis, respectively; or otherwise, coda max syllabification seems rather counterintuitive in these cases. Therefore, there is no reason to assume that the system of early Germanic languages does not license the $\mathrm{C} j$ sequence in the onset position. Instead, it seems to be better to conceive the $\mathrm{C} j$ as an onset cluster, since the conception makes possible a uniform characterization.

Finally, in theoretical terms, our approach with West Germanic gemination (32) is simpler and more highly-valued than an approach with the two rules, partly because a fewer number of rules are favorable and partly because it is not the case that the $\mathrm{C}$ of $\mathrm{C} j$ is syllabified either into the preceding coda or into the following onset.

It naturally follows from the above discussion that the $\mathrm{C}$ of $\mathrm{C} j$ is syllabified into the following onset, that segmentally-formulated rules such as gemination and $j$-deletion are not substitutable for prosodically-formulated WGmc gemination (32), and that an "onset-max" approach is preferable to a coda max approach as far as Old English prosody is concerned. 
lying form is light in (33a) and heavy in (33b). Second, the minimal contrast above is not accounted for by Okazaki's syllable-based feet, since there seems to be no way to formulate vocalization as stated in the previous section, or West Germanic gemination. Third, even if he managed to formulate the two rules in some way or other, his assumed high vowel deletion (17) might produce an aberrant surface form * [stycc], because it can apply repeatedly as long as the structural description is met (this point was also mentioned with regard to (18) in section 3.1.):

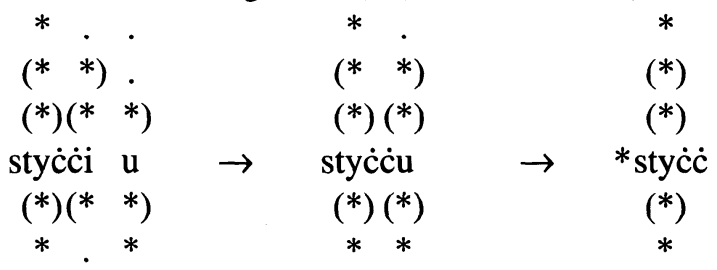

\section{Summary and Concluding Remarks}

We have thus far presented a uniplanar account of Old English prosody and adduced several pieces of evidence for it by examining extraordinary stress, high vowel deletion, resolution, Sievers's Law, and West Germanic gemination. Since the possibility of our uniplanar account relies especially on postulating that Old English and other early Germanic languages have moraic feet, the arguments so far also support a mora-based account in general. The claim that these languages are mora-counting is made by Liberman (1979) as well as Lahiri and Hulst (1987), Kaminashi (1989), and D \& L. Liberman (1979) remarks that "there can be little doubt that at the earliest reconstructible stages Germanic dialects were mora-counting ... The end of mora-counting is the main event in the history of Germanic quantity... Germanic languages, with the partial exception of Danish, began to count syllables, not moras."

Turning to the grammar of early Germanic languages, they are considered to share the following system, although some details are variant across languages or dialects:

(35) a. parameter settings (1)

b. resolution (22)

c. stress movement

d. clash deletion

e. WGmc gemination (32) 
$\begin{array}{ll}\text { f. } & \text { vocalization (27) } \\ \text { g. high vowel deletion (16) }\end{array}$

These rules apply in the order presented above. With the historical development of the English language, (35b) and $(35 \mathrm{e}-\mathrm{g})$ have been obsoleted, whereas $(35 \mathrm{c}, \mathrm{d})$, which are observed in any quantity-sensitive language, have survived. The survival of $(35 \mathrm{c}, \mathrm{d})$ should be due to the fact that their applicability is determined by a universal principle to avoid a stress clash and to accomplish eurhythmy. As for the parameter settings, moraic feet and superfeet, the latter of which are assigned from right to left, have been "conflated" and developed into quantity-sensitive and syllable-counting feet assigned from right to left. The dominance of a phonological word has changed from left-headed to right-headed probably on account of the influence of Latinate words. The introduction of Latinate words has also given rise to extrametricality in the history of English.

\section{REFERENCES}

Dresher, Bezalel E. (1978) Old English and the Theory of Phonology, Doctoral dissertation, University of Massachusetts. [Reproduced by Garland, New York, 1985]

Dresher, B. Elan and Aditi Lahiri (1991) "The Germanic Foot: Metrical Coherence in Old English," Linguistic Inquiry 22, 251-286.

Halle, Morris and Jean-Roger Vergnaud (1987) An Essay on Stress, MIT Press, Cambridge, MA.

Haraguchi, Shosuke (1991) A Theory of Stress and Accent, Foris, Dordrecht.

Haraguchi, Shosuke and Shin-ichi Tanaka (1992) "Moora no Yakuwari to Seisitu ni kansuru Soogooteki Kenkyuu (An Integrated Theory of Mora: Its Role and Nature)," Nihongo no Moora to Onsetu Koozoo ni kansuru Soogooteki Kenkyuu (Integrated Studies on Mora and Syllable Structure in Japanese), report of a research project under a grant from the Ministry of Education, ed. by Shosuke Haraguchi, 1-7, University of Tsukuba.

Hayes, Bruce (1989) "The Prosodic Hierarchy in Meter," Phonetics and Phonology 1: Rhythm and Meter, ed. by Paul Kiparsky and Gilbert Youmans, 201-260, Academic Press, San Diego.

Hyman, Larry M. (1985) A Theory of Phonological Weight, Foris, Dordrecht.

Kaminashi, Keiko (1989) "Old English Stress, High Vowel Deletion and Gemination: Two Prosodic Plane Approach,” Studia Linguistica 43, 77-118. 
Keyser, Samuel J. and Wayne O'Neil (1985) Rule Generalization and Optionality in Language Change, Foris, Dordrecht.

Kiparsky, Paul (1973) “'Elsewhere' in Phonology,” A Festshrift for Morris Halle, ed. by Stephen R. Anderson and Paul Kiparsky, 93-106, Holt, Rinehart, and Winston, New York.

Lahiri, Aditi and Harry van der Hulst (1987) “On Foot Typology," NELS 18, 287-299.

Liberman, Anatoly (1979) "On the History of Quantity in Germanic," Current Issues in the Phonetic Sciences, ed. by H. Hollien and P. Hollien, John Benjamins, Amsterdam.

McCully, Richard M. and C. B. Hogg (1990) "An Account of Old English Stress," Journal of Linguistics 26, 315-339.

Okazaki, Masao (1987) On High Vowel Deletion in Old English, MA theis, University of Tsukuba.

Okazaki, Masao (1989) "On Secondary Stress in Old English," Tsukuba English Studies 8, 139-158.

Selkirk, Elisabeth O. (1984) Phonology and Syntax: The Relation between Sound and Structure, MIT Press, Cambridge, MA.

Sievers, Eduard (1893) Altgermanische Metrik, Max Niemeyer, Halle.

Suphi, Menekse (1988) “Old English Stress Assignment," Lingua 75, 171-202.

Tanaka, Shin-ichi (1990a) "Intrasyllabic Boundaries: A Violation of the Strict Layer Hypothesis," Tsukuba English Studies 9, 1-38.

Tanaka, Shin-ichi (1990b) "Old English as a Mora-Counting Language: Stress and Its Relation to High Vowel Deletion," Tsukuba English Studies 9, 39-60.

Tanaka, Shin-ichi (1991a) "Three General Principles and Their Related Rules in Prosodic Theory," Tokyo Linguistics Forum 4, 145-158.

Tanaka, Shin-ichi (1991b) "A Reexamination of Old English Prosody," Tsukuba English Studies 10, 27-49.

Tanaka, Shin-ichi (1992a) "Stress Clash and Its Resolutions: Toward a Theory of Rhythmic Alternation," talk presented at the monthly meeting of the Tsukuba English Linguistics Colloquium held on January 19, 1992.

Tanaka, Shin-ichi (1992b) "Accentuation and Prosodic Constituenthood in Japanese," Tokyo Linguistics Forum 5, 195-216.

Tanaka, Shin-ichi (1992c) “Aspects of Minimality and Prosodic Constituenthood," Tsukuba English Studies 11, 75-116.

Yokotani, Teruo (1991) "The Strict Binary Hypothesis and OE High Vowel Deletion," Ronshuu 15, 1-17, Aoyamagakuin University. 
Institute of Literature and Linguistics

University of Tsukuba Tennodai 1-1-1, Tsukuba-shi

Ibaraki, 305 